\title{
Assessment of Agricultural Nutrient Surplus in Pig-concentrated Region in Korea
}

Yejin Lee, and Hong-Bae Yun*

Soil and Fertilizer division, National Academy of Agricultural Science, RDA, Suwon-si, Gyeonggi-do, 441-707, Korea

(Received: October 24 2013, Accepted: November 18 2013)

\begin{abstract}
Assessment of nutrient balance in region unit is important to make a decision on nutrient management in agriculture. In this study, the nutrient demand in arable land and nutrient supply from livestock manure and chemical fertilizer were estimated from pig-concentrated areas. Three regions $(H, I$ and $J)$ were selected on the basis of pig numbers per unit area of arable land. In $\mathrm{H}$ and $\mathrm{I}$ regions, nitrogen amount from pig manure occupied about 50\% of total livestock manure. Nutrient supply was three times higher compared to the nutrient demand in each of 3 regions. Soil available phosphate of higher pig-populated area in regional unit was higher than less populated livestock area. Therefore, livestock manure-derived regional management and monitoring of soil nutrient contents is necessary for the minimization and improvement of nutrient surplus.
\end{abstract}

Key words: Pig concentration region, Nutrient surplus, Livestock manure

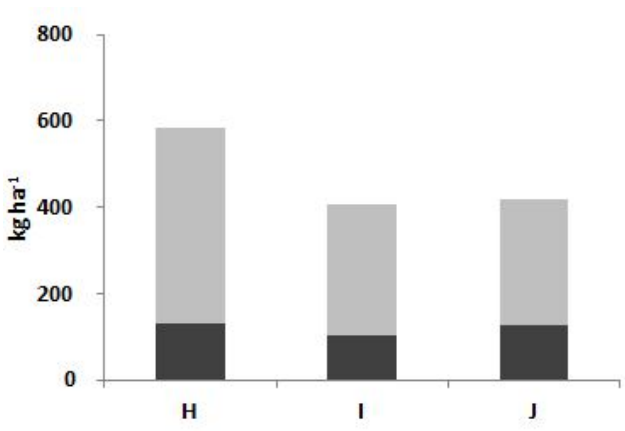

(a) Nitrogen

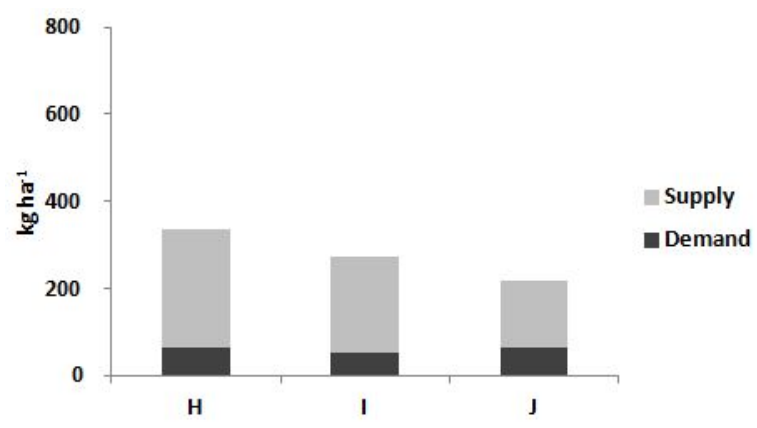

(b) Phosphorus

Nitrogen and phosphorus supply and demand per unit area of arable land in $\mathrm{H}$, I and $\mathrm{J}$ regions.

*Corresponding author : Phone: +82312900319, Fax: +82312900208, E-mail: hbaeyun@korea.kr

${ }^{\S}$ Acknowledgement: This paper is the result of the project (PJ00856902) conducted by Rural Development Administration. 


\section{Introduction}

폐기물의 해양 배출 금지에 관한 협정인 런던의정서가 발효됨에 따라 우리나라는 2012년부터 가축분뇨 해양배출 이 전면 금지되었다. 원유 쿼터제가 시행되고 있는 젖소를 제외한 주요 축종의 사육두수는 유지 또는 일부 증가하는 추세이나 전국 농경지 면적은 감소하고 있어 결과적으로 가 축분뇨를 수용할 수 있는 농경지의 양분부하가 우려되는 상 황이다. 가축사육이 밀집될 경우 분뇨 및 오폐수가 유출되 어 하천의 부영양화와 악취 등 비점오염을 유발할 가능성이 커지고, 전체적인 양분수지를 높이는 원인이 된다.

$\mathrm{OECD}$ 농업환경지표 중 농업양분지표는 비료사용량, 가 축분뇨 발생량 등 농경지 양분 투입량과 농산물 생산에 의 한 반출량을 구하여 양분수지를 평가하는 것으로서 $\mathrm{OECD}$ 회원국의 농업 정책을 평가하기 위한 지표로 활용되는데 (Kim and Kim, 2005), 1985년부터 2006년까지 우리나라의 질소, 인산 수지는 가축 사육두수 증가로 인해 높은 수준을 유지하는 것으로 나타났으며 (Kim et al., 2008), OECD 주 요 회원국의 양분수지를 비교한 결과 우리나라와 같이 집약 적인 농업을 하는 나라에서 높은 양분수지를 나타내 정책적 으로 양분수지 개선을 위한 노력이 필요한 것으로 나타났다 (Lee et al., 2002).

전국적으로 양분 부하량을 평가하기 위하여 시군 단위로 양분정보를 관리하는 시스템 구축 연구가 수행되었으며 (Lee et al., 2006), 지역 사례 연구로는 경기도 내 시군에서 가축 분뇨 유래 양분 발생량과 잉여량을 산정하고 (Kang et al., 2008), GIS를 이용하여 축산농가와 가축분퇴비 제조시설 분포, 양분 잉여량 및 필요량을 분석하는 프로그램 개발 연 구가 수행된 사례가 있다 (Roh et al., 2010).

본 연구에서는 우리나라에서 돼지 사육두수가 많은 지역 을 대상으로 돈분뇨로부터의 양분 발생량과 농경지 양분 필 요량을 분석하여 잠재적 양분 잉여량을 평가하고, 해당 지 역의 농경지 양분 함량을 분석하여 양분수지 개선을 위한 방안을 모색하고자 하였다.

\section{Materials and Methods}

대상지역 선정과 잠재적 양분 부하량 분석 전국에서 농경지 단위면적당 돼지 사육두수가 많고 행정구역이 다른 3 개 시군을 대상지역으로 선정하였다. 통계자료는 통계청, 행정 통계 2010년도 자료를 활용하였으며, 가축분뇨로부터의 양분 발생량은 국립축산과학원의 가축분뇨 배출 원단위와 가축분 뇨 비료성분 함량 (NIAS, 2008)으로 산정하였다 (Table 1). 잠재 적 양분 부하량 산정을 위하여 통계자료의 화학비료 공급량과 가축분뇨 양분 발생량으로 투입량을 구하고, 작물별 재배면적 과 국립농업과학원의 작물별 시비처방기준 (NAAS, 2010)의 비료 표준사용량을 기준으로 양분 필요량을 계산하였다. 가축 분 유래 질소는 퇴비화에 의한 질소 손실량 $40 \%$ 를 감안하였 으며 (Lee et al., 2009), 자연적으로 공급되거나 제거되는 양 분은 환경조건에 따라 다르기 때문에 본 연구에서는 질소고정 이나 작물 수확으로 인한 양분 손실량은 고려하지 않았다.

돼지 밀집, 비밀집 지역의 토양화학성 분석 돼지 밀 집정도가 농경지의 양분 집적에 영향을 미치는지 비교하기 위하여 3 개 시군의 읍면을 돼지 밀집과 비밀집 지역으로 구 분하여 농경지 토양의 화학성을 분석하였다. 돼지 밀집 지 역은 농경지 단위면적 (ha) 당 사육 두수가 20마리 이상인 지역으로 구분하였다. 토양 화학성은 국립농업과학원의 토 양 및 식물체 분석법 (NIAST, 2000)에 준하여 분석하였으며, 밀집, 비밀집 지역 간 토양 화학성 차이는 $\mathrm{R}$ version 3.0.2 의 Welch two sample t-test로 통계 분석하였다.

\section{Results and Discussion}

잠재적 양분 발생량과 양분 필요량 3 개 시군의 가축 사육두수와 농경지 면적은 Table 2 와 같다. 가축사육두수는 $\mathrm{H}$ 시군이 가장 많았으나 농경지 면적은 $\mathrm{J}$ 시군이 가장 넓어 농경지 단위면적 (ha)당 돼지 사육두수는 $\mathrm{H}$ 시군에서 35 마 리, I 시군은 23 마리, J 시군은 12 마리였다.

3 개 시군에서 돈분 유래 양분 발생량이 총 가축분뇨 유래

Table 1. Livestock manure production amount and nutrient content.*

\begin{tabular}{ccccccc}
\hline \hline \multirow{2}{*}{ Animal type } & \multicolumn{2}{c}{$\begin{array}{c}\text { Amount of manure production } \\
\text { (kg/day-an animal) }\end{array}$} & \multicolumn{2}{c}{$\begin{array}{c}\text { Nitrogen content } \\
(\%)\end{array}$} & \multicolumn{2}{c}{$\begin{array}{c}\text { Phosphorus content } \\
(\%)\end{array}$} \\
\cline { 2 - 7 } & Feces & Urine & Feces & Urine & Feces & Urine \\
\hline Korean cattle & 8.0 & 5.7 & 0.50 & 0.68 & 0.60 & 0.07 \\
Dairy cattle & 19.2 & 10.9 & 0.33 & 1.02 & 0.49 & 0.27 \\
Pig & 0.88 & 1.74 & 0.96 & 0.80 & 0.83 & 0.09 \\
Layer chicken & 0.1247 & - & 1.39 & - & 0.29 & - \\
Broiler chicken & 0.0855 & - & 1.19 & - & 0.62 & - \\
\hline
\end{tabular}

* NIAS (2008) 
Table 2. Number of livestock and arable land area in the 3 regions.*

\begin{tabular}{|c|c|c|c|c|c|c|}
\hline \multirow{2}{*}{ Regions } & \multicolumn{4}{|c|}{-------- Number of livestock -------- } & \multicolumn{2}{|c|}{-- Arable land(ha) -- } \\
\hline & Korean cattle & Dairy cattle & Pig & Chicken & Paddy & Upland \\
\hline $\mathrm{H}$ & 62,759 & 4,297 & 498,891 & $2,800,837$ & 10,548 & 3,860 \\
\hline I & 19,772 & 24,333 & 397,116 & $3,440,000$ & 9,747 & 7,486 \\
\hline $\mathrm{J}$ & 73,570 & 6,710 & 274,523 & $6,139,744$ & 16,129 & 6,754 \\
\hline
\end{tabular}

* MFAFF, 2010

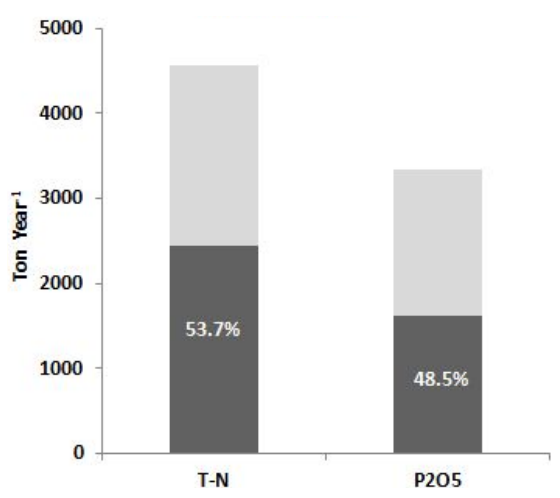

(a) H region

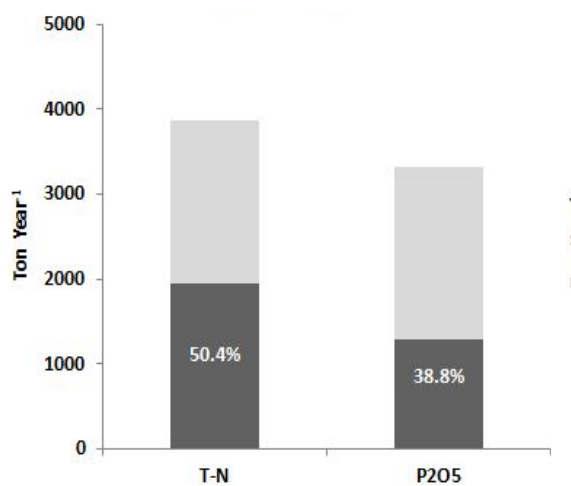

(b) I region

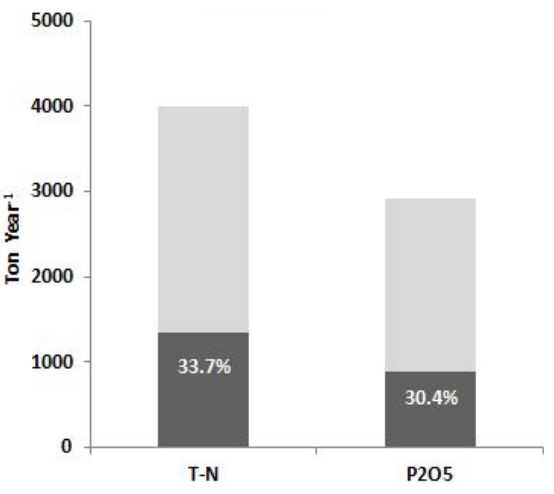

(c) J region

Fig. 1. Potential nutrient amount generated by livestock manure and percentage of pig manure in a) $\mathbf{H}$, b) $\mathbf{I}$ and c) $\mathrm{J}$ regions.

Table 3. Annual nutrient demands of arable land in 3 regions.

\begin{tabular}{|c|c|c|c|c|c|c|c|c|}
\hline \multirow{2}{*}{ Regions } & \multicolumn{4}{|c|}{ - } & \multicolumn{4}{|c|}{----------- $\mathrm{P}_{2} \mathrm{O}_{5}$ demand (ton) - } \\
\hline & Paddy & Upland & Orchard & Total & Paddy & Upland & Orchard & Total \\
\hline $\mathrm{H}$ & 1286 & 576 & 40 & 1902 & 632 & 246 & 21 & 899 \\
\hline I & 1228 & 343 & 228 & 1799 & 603 & 150 & 121 & 874 \\
\hline $\mathrm{J}$ & 2263 & 441 & 189 & 2893 & 1164 & 221 & 97 & 1482 \\
\hline
\end{tabular}

Table 4. Annual potential nutrient supplies from livestock manure and chemical fertilizer.

\begin{tabular}{|c|c|c|c|c|c|c|}
\hline \multirow[b]{2}{*}{ Regions } & \multicolumn{3}{|c|}{ 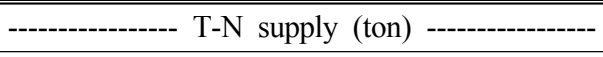 } & \multicolumn{3}{|c|}{ - - $\mathrm{P}_{2} \mathrm{O}_{5}$ supply (ton) - - } \\
\hline & $\begin{array}{c}\text { Livestock } \\
\text { manure }\end{array}$ & $\begin{array}{l}\text { Chemical } \\
\text { fertilizer }\end{array}$ & Total & $\begin{array}{c}\text { Livestock } \\
\text { manure }\end{array}$ & $\begin{array}{l}\text { Chemical } \\
\text { fertilizer }\end{array}$ & Total \\
\hline $\mathrm{H}$ & 4,554 & 1971 & 6,525 & 3,328 & 622 & 3,950 \\
\hline I & 3,862 & 1338 & 5,200 & 3,316 & 487 & 3,803 \\
\hline $\mathrm{J}$ & 3,987 & 2647 & 6,634 & 2,925 & 579 & 3,504 \\
\hline
\end{tabular}

양분 발생량에서 차지하는 비율을 보면 H 시군과 I 시군은 질소의 약 50\% 이상, 인산의 약 40-50\% 정도가 돈분에서 발생될 수 있는 것으로 나타났다. 반면에 $\mathrm{J}$ 시군은 타 축종 의 비율이 높아 돈분에 의한 양분 발생비율은 약 $30 \%$ 정도 해당되는 것으로 나타났다 (Fig. 1).

3 개 시군의 농경지 유형별 양분 필요량을 분석한 결과, 전체 농경지에서 필요한 질소, 인산 함량 중 논이 차지하는 비율이 가장 높았는데, H와 I 시군에서는 약 $68 \sim 70 \%, \mathrm{~J}$ 시 군은 약 $78 \%$ 가 논에서 필요한 것으로 나타났다. $\mathrm{H}$ 시군에 서는 전체 양분 필요량 중 밭작물에서 약 $30 \%$ 정도 필요한
것을 알 수 있었고, I 시군은 밭작물에서 약 $17 \sim 19 \%$, 과수 에서 약 $13 \%$ 정도 필요한 것으로 나타났다(Table 3).

가축분뇨에 의한 연간 양분 총량을 추정해보면 질소의 경우 $\mathrm{H}$ 시군에서 약 4500 톤, I와 J 시군은 약 4000 톤, 인산 은 약 3000 에서 3300 톤이 공급될 수 있는 것으로 나타나 농 경지 양분 필요량을 초과하는 것으로 나타났다. 그럼에도 불구하고 화학비료 공급량은 양분 필요량에 상당하는 것으 로 나타났다 (Table 4).

농경지 단위면적당 양분 필요량과 화학비료와 가축분뇨 에 의한 양분 공급량을 비교했을 때 3 개 시군 모두 질소와 


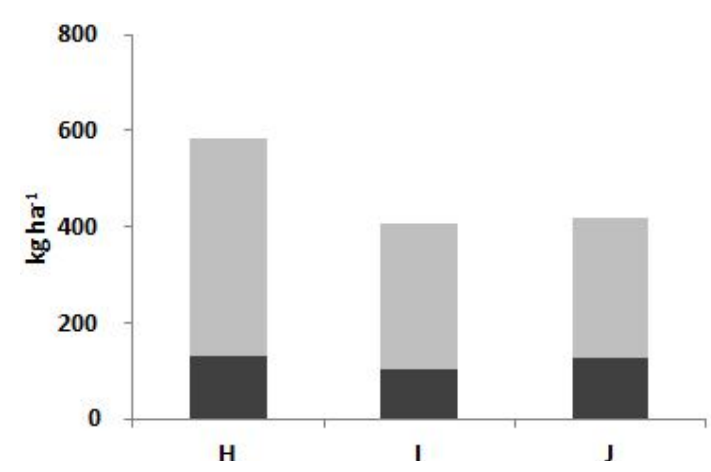

(a) Nitrogen

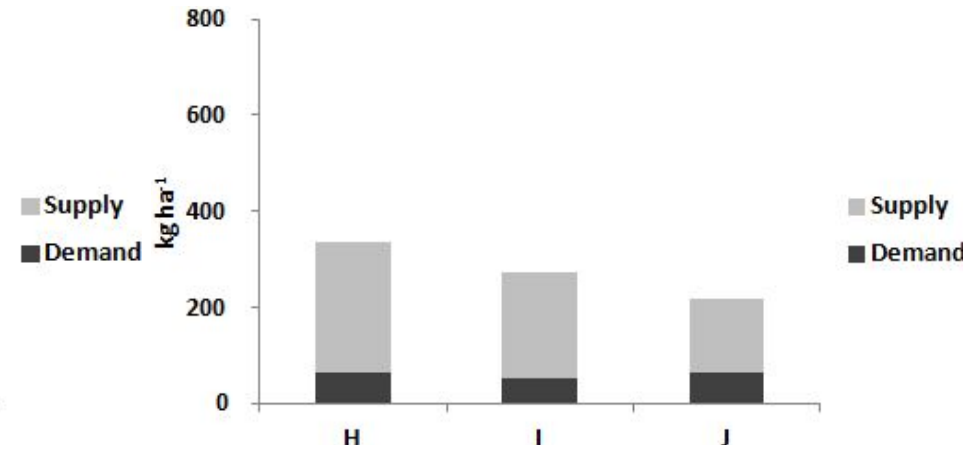

(b) Phosphorus

Fig. 2. Nitrogen and phosphorus supply and demand per unit area of arable land in $H$, I and $J$ regions.

Table 5. Soil nutrient contents of pig concentrated (PC) and non-concentrated (PNC) area in 3 regions.

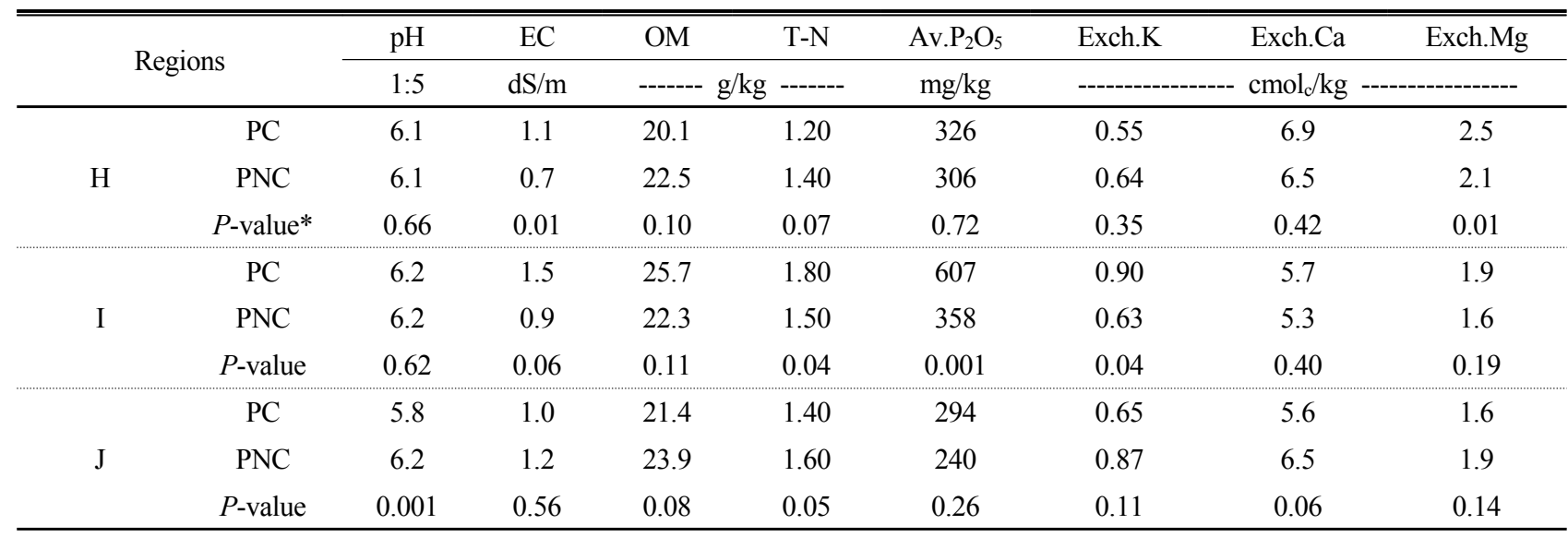

* Welch two sample t-test (significant level $P<0.05$ ) $(\mathrm{R}$ version 3.0.2)

인산이 과다 공급될 우려가 있는 것으로 나타났다 (Fig. 2). 특히 H와 I 시군은 가축분뇨 유래 질소의 약 $50 \%$ 정도가 돈 분에 의해 발생될 수 있어 돈분 자원화를 통하여 양분을 효 율적으로 공급할 수 있는 여건을 마련하는 것이 중요할 것 으로 판단된다. 축산업이 발달된 일부 선진국에서는 농경지 소유면적 당 가축분뇨 발생량을 정하여 가축 사육두수를 제 한하는 정책을 시행하고 있으나 (Song et al., 2004), 지역 별로 가축 사육두수를 제한하는 것은 축산업 발달에 영향을 미칠 수 있으므로 다양한 분석을 통하여 합리적으로 양분을 분산시킬 수 있는 방안이 필요하다.

돼지 밀집과 비밀집 지역 간 토양 양분 함량 비교 3 개 시군 내에서 농경지 단위면적당 돼지 사육두수가 20 마 리 이상인 읍면을 밀집지역, 그 이하인 읍면을 비밀집지역으 로 구분하여 토양화학성의 평균값을 비교하였다 (Table 5).

유효인산의 경우 농경지 단위면적당 돼지 사육두수가 높 은 H와 I 시군에서 다소 높게 나타났으며, 특히 I 시군은 돼 지사육밀도가 높은 읍면에서 유효인산 함량이 약 2 배가량 높은 현상을 보임에 따라 돈분뇨의 적절한 투입 대책이 필 요하다고 판단된다.

\section{Conclusions}

본 연구에서는 돼지 사육두수가 많은 3 개 시군을 선정하 여 가축분뇨 유래 양분 발생량과 농경지 양분 필요량을 평 가하고, 돼지 밀집 여부에 따른 토양화학성을 비교하였다. 3 개 시군 모두 양분 필요량보다 2 3배 많은 양분이 공급될 가능성이 있고, 일부 시군에서는 돈분 유래 질소 발생량이 전체 주요 축종의 $50 \%$ 이상을 차지하는 것으로 나타나 돈분 뇨 자원화를 통한 양분 공급이 유용할 것으로 판단되었다. 각 시군 내에서 돼지 사육 밀집, 비밀집 읍면을 구분하여 토 양 화학성을 분석한 결과, 돼지 밀집 읍면에서 유효인산 함 량이 높게 나타나 가축 밀집이 농경지 양분함량에 영향을 미칠 수 있는 것으로 나타났다.

\section{Acknowledgement}

본 연구는 농촌진흥청 국립농업과학원 농업과학기술 연 구개발사업 (과제번호 : PJ00856902)의 지원에 의해 이루어 졌으며, 이에 감사드립니다. 


\section{References}

Kang, C.S., A.S. Roh, J.W. Lim, K.Y. Park and Y.K. Kim. 2008 Study on the evaluation of nutrient balance by the production of livestock excretion in the Paldang area in Gyeonggi-do. Korean J. Soil Sci. Fert. 43:91-92

Kim, C.G. and T.Y. Kim. 2005. Directions for linkages between policy measures and the OECD agricultural environmental indicators. Korean J. Environ. Agri. 24(3):303-313.

Kim, P.J., Y.B. Lee, Y. Lee, H.B. Yun and K.D. Lee. 2008. Evaluation of livestock manure utilization rates as agricultural purpose in developed OECD countries by using nutrient balanes. Korean J. Environ. Agri. 27(4):337-342.

Lee, Y., H.B. Yun and Y.B. Lee. 2008. Estimation of nitrogen loss from pilot and large scale composting by ammonia measurement and N/P ratio changes. Bulgarian J. of Ecological Sci. 7(4):13-15.

Lee, Y., H.B. Yun, J.S. Noh and J.K. Cho. 2006. Construction of regional nutritional information system for nutrient management. Korean J. Soil Sci. Fert. 39:129.
Lee, Y., S.C. Kim and Y.H. Park. 2002. Development of nutrient balance indicatior, RDA, Suwon, Korea.

MFAFF. 2010. Agricultural and forestry statistical yearbook. Ministry for Food, Agriculture, Forestry and Fisheries, Korea.

NAAS. 2010. Fertilization standard on crops(Revised ed.). National Academy of Agricultural Science, Suwon, Korea.

NIAS. 2008. The study of re-establish the amount and major compositions of manure from livestock. RDA, Suwon, Korea.

NIAST. 2000. Method of soil and plant analysis. National Institute of Agricultural Science and Technology, RDA, Suwon, Korea.

Roh, A.S., C.S. Kang, J.S. Park and S.K. Kim. 2010. GIS program for environment-friendly management of livestock wastes. Korean J. Soil Sci. Fert. 45:351-352.

Song, J.H., C.K. Kim, D. Heo and S.J. Lim. 2004. A study on the introduction of regional maximum load system of liestock numbers, KREI, Seoul, Korea. 